\title{
The Relationship between Brand Personality and Consumers' Personality among Students
}

\author{
Roya Anvari1,2 \\ Sobia Irum² \\ ${ }^{1}$ Faculty of Literature and Humanities, Islamic Azad University of Sarab, East Azarbaijan, Iran \\ 2Department of HRD, Faculty of Management, Universiti Teknologi Malaysia, 81310 UTM Johor Bahru, Johor, Malaysia \\ Email: roya.anvari@utm.my
}

Doi:10.5901/mjss.2015.v6n5p175

\section{Abstract}

\begin{abstract}
There are numerous cases in which when a particular brand launches a new product, customers or consumers would start to queue days before the launch of the product. Examples of such products are Apple IPhones and Samsung Galaxy among others. This phenomenon is a familiar occurrence in several countries such as New York, Japan and Singapore. Relating to brand personality, it was found to be significantly related to consumers' personality. Compared to other studies, this study focuses on finding the relationship and effect of brand personality on consumer personality in order to identify the reasons as to why people were attracted to a particular product. The aim of this study was to investigate the correlation between brand personality and consumers' personality among the undergraduate students in the Faculty of Management at Universiti Teknologi Malaysia. A descriptive-correlation research was conducted using questionnaires such as Aaker's Brand Personality and big five personality. Based on random sampling, 242 questionnaires were collected from students in Faculty of Management, Universiti Teknologi Malaysia. The data was analyzed using Data Descriptive Statistics, Pearson Correlation, and Multiple Regression. The results indicated that the dimension of brand personality and dimension of consumers' personality were highly correlated, in which both had high significance. Moreover, the multiple regression showed that brand personality could affect consumers' personality. The results of this study can prove the relation between brand personality and consumers' personality. It showed that through the brands that consumers used, the personality of the consumers could be predicted according to the knowledge about brand personality.
\end{abstract}

Keywords: Brand Personality, Consumer's Personality, Self - Congruence

\section{Introduction}

According to Cohen (2010), despite the downturn of economy in the United States, customers still waited for the new IPhone 3GS to be launched, in which the sales of IPhone hit 1 million in just 3 days. In Malaysia, some individuals had to queue up for approximately two days before a particular phone is launched, in the sense that some started their wait from 3am outside the shop in order to be the first to get a Samsung Note 4 (Aminuddin, 2014). Similar cases also occurred in Singapore, Germany, Japan and Australia among others. Thus, this study seeks to identify the reason behind a product's association with consumers; by conducting research on the brand personality of a product.

Although some businesses have high demands from customers, they still face the problem of dealing with customers, partners and employees in a virtual way. "Personality" can make a particular brand stand out in terms of the difference between the product and other products, along with stories about the product that could be conveyed to customers (Bhargava, 2008). The study of consumer psychology believes that consumers like to purchase something that is similar to themselves (Ekhlassi, Nezhad, Far, \& Rahmani, 2012). According to Park (2011), consumers often prefer and would choose brands which could affirm their personality and enhance their sense of self. Most of the studies measured brand personality with brand love, brand loyalty, brand image, the advertising and personality traits (Cohen, 2010; Ekhlassi et al., 2012; King, 2007; Park, 2011) and brand personality toward specific brand (Champniss \& Vila, 2011; Ferrandi, Merunka, Valette-Florence, \& Barnier, 2002; Mikkelsen; Thomas \& Sekar, 2008; Till \& Heckler, 2009). However, these studies did not focus on the direct effect and relationship of brand personality on consumers' buying decision. Thus, this study's focus was on identifying whether consumers' decisions could be affected by a product's brand personality, in which consumers might choose products with brand personality that is in congruence with their own personality traits. In this study, the concept of measuring the effect of brand personality on consumer personality was considered new in figuring out consumers' buying approach. 


\section{Literature Review}

\subsection{The Personality of Undergraduate Students}

Traits theories try to identify the consistencies of individual's behavior (Renner, Feldman, Morrissey, Mae, \& Major, 2011). Everyone has particular traits and the difference lies in the degree of those traits (Renner et al., 2011). For example, you have two friends, whereby one is "friendly" and another is "unfriendly". This means that the one who is described as friendly has a higher degree of traits "friendliness" compared to the unfriendly one, instead of saying that the "unfriendly" person does not have the "friendliness" trait (Renner et al., 2011).

The five factor model that is commonly used is the big five Factor which consists of Neuroticism, Extraversion, Openness, Agreeableness, and Conscientiousness. Individuals with high Openness are imaginative, witty, original, and artistic whereas individuals low in Openness are shallow, plain or simple (Friedman \& Schustack, 2011). Meanwhile, individuals with high Conscientiousness are dependable, persevering, organized and responsible, while those low in Conscientiousness are impulsive, careless, disorderly and undependable (Friedman \& Schustack, 2011). These factors are useful in the prediction of job success (Engler, 2009).

In addition, individuals high in Extraversion are energetic, enthusiastic, dominant, sociable and talkative while those low in Extraversion have opposite traits. As for Agreeableness, individuals high in this aspect tend to be friendly, cooperative, trusting and warm compared to individuals low in Agreeableness who are often cold, quarrelsome, and unkind (Friedman \& Schustack, 2011). Lastly, Neuroticism refers to the tendency of experiencing negative emotions (Shoda, Mischel, \& Smith, 2004). Neurotic individuals are usually nervous, tension, moody and worry a lot (Friedman \& Schustack, 2011).

Therefore, the first objective was to identify the level of personality of respondents in Faculty of Management; that is to determine the dominant personality trait among the students. The finding on the respondents' personality was crucial in identifying its relationship with brand personality.

\subsection{The Brand Personality of the Product Consume by the Undergraduate Students}

According to Aaker (1997), brand personality is defined as "a set of human characteristics associated with a brand". Brand personality also contains demographic features such as gender, age and social class in which the brand could be related to users or the product's attribution (Lin, 2010), For example, individuals with higher social status prefer to drive the Mercedes instead of cheaper cars which do not match their status.

Aaker's brand personality has five dimensions, known as Sincerity, Excitement, Competence, Sophistication, and Ruggedness (Aaker, 1995). Sincerity has 3 facets which are down-to-earth, honest and wholesome and honest. Products related to Sincerity could be Hallmark and Coca-cola (Carlson, Donavan, \& Cumiskey, 2009). Meanwhile, the dimension of Excitement has 4 facets which are Daring, Spirited, Imaginative, and Up-to-date. Brands with this Excitement trait are Porsche, Benetton and Absolut (Franzen \& Moriarty, 2009).

In addition, the Competence dimension has 3 facets, that are intelligent, reliable and successful (Aaker, 1995). The brands that can used to describe this dimension are IBM, American Express, and ABN AMRO (Franzen \& Moriarty, 2009). The facets of Sophistication are class and charming like Mercedes, Channel and BMW (Carlson et al., 2009; Thomas \& Sekar, 2008). Lastly, Ruggedness has 2 facets; outdoorsy and tough. Brands such as Levis and Nike are associated with the ruggedness trait (Franzen \& Moriarty, 2009; Thomas \& Sekar, 2008).

This objective was to identify the level of product's brand personality among students in Faculty of Management. Knowing the type of brand personality among the students helps to understand the brand personality that is most commonly used and could identify its relation with consumers' personality.

\subsection{The Relationship Between Brand Personality and Consumers' Personality}

The Aaker's model of brand personality is using the dimension of big five model, thus both measures have high similarity (Abdul \& Jevons, 2009). The big five personality is the personality trait which has high correlation to brand personality and according to Lin (2010), there was a significant correlation between brand personality and personality trait.

The Sincerity dimension was highly correlated with the big five Agreeableness trait (Aaker, 1995). Previous research have shown that the Sincerity trait could be linked to the traits of Agreeableness and Conscientiousness (Geuens, Weijters, \& De Wulf, 2009), thus the hypothesis ( $\mathrm{H1a}$ ) is developed for this study. Meanwhile, the Excitement dimension was correlated with the Openness trait (Aaker, 1995), which then led to the development of the hypotheses 
(H1b) for this study. However, according to Geuens et al. (2009), the dimension of Excitement was the same as with the trait of Extraversion. It was also found that Excitement had positive relation with the traits of Extraversion and Conscientiousness (Ghorbani \& Mousavi, 2014).

Conceptually, the Competence dimension was the same as the trait of Conscientiousness such as being thorough, efficient, and organized (Aaker, 1995). Ghorbani and Mousavi (2014) found a significant relationship between Conscientiousness and Competence too. Besides, Competence was also found to be correlated with Conscientiousness and Extraversion (Geuens et al., 2009), thus the hypothesis (H1c) is developed.

For Sophistication and Ruggedness dimensions, they were not found to have any correlation with the big five Personality dimensions (Geuens et al., 2009). The Sophistication dimension had not much similarity with Extraversion and the Ruggedness dimension did not have same traits as that for Neuroticism (Aaker, 1995). According to Aaker (1995), using Sophistication to compare with Extraversion and Ruggedness to compare with Neuroticism, the hypotheses $(\mathrm{H} 1 \mathrm{c})$ \& $(\mathrm{H} 1 \mathrm{~d})$ are developed.

\section{Methods}

\subsection{Design}

This study used the descriptive- correlational research to find the relationship between brand personality with consumers' personality. The descriptive research was conducted using surveys while the correlational research aimed to find the relation between the two variables of interest and also to use brand personality to predict consumers' personality.

\subsection{Population and sampling}

The population in this study was around 700 undergraduate students in Faculty of Management in Universiti Teknologi Malaysia. According to Krejcie and Morgan (1970), 248 of questionnaires must be sent out to the sample population using the random sampling method.

\subsection{Data collection method}

This study used questionnaires to collect the primary data. As for the secondary data, they were obtained from articles, journals, previous case studies, books and sources from the internet. On 13 distributed but only 242 of the questionnaires were returned, thus gaining a return rate of $91 \%$.

\subsection{Measurements}

Brand personality was measured using adapted five-dimensional (Sincerity, Excitement, Sophistication, Ruggedness, Competence) scales with 45 items developed by Aaker (1995).

In addition, the big five personality was measured using adapted five-dimensional scales (Extraversion, Openness, Neuroticism, Conscientiousness, Agreeableness) with 44 items developed by John, Donahue and Kentle in 1991 (John \& Srivasta, 1999).

\subsection{Validity and Reliability}

The validity test was taken from previous study, which showed the value of the instrument being higher than 0.7 . Meanwhile, the reliability test was measured by conducting a pilot study, with the score of Cronbach alpha being averagely higher than 0.75 . The reliability of the questionnaire are as shown in table 3.5 , in which the Cronbach alpha value for Brand Personality was 0.60 and The total Cronbach Alpha of big five personality was 0.96 .

\subsection{Data Analysis}

In this study, the SPSS version 18.00 was used to analyze the results of the questionnaires. Descriptive statistics and Pearson correlation were used to test the correlation between brand personality and consumers' personality. The multiple regression was carried out to identify the dimensions of brand personality which have significant effect on the personality of consumers. Besides that, the direct influence of brand personality towards personality was also examined. 


\section{Result}

\subsection{Demographic Characteristics}

Table 1 shows the demographic characteristics of the respondents, in which 80.6 percent of the respondents were female and only $19.4 \%$ of the respondents were male. The age of the respondents was between 20 years old to approximately 24 years old. Specifically, $35.5 \%$ of the respondents were 22 years old, and only $7.4 \%$ of respondents were 24 or more than 24 years old. Lastly, $35 \%$ of them were third year students, and only $2.5 \%$ were first year students.

Table 1: Respondent Demographics

\begin{tabular}{ll}
\hline Characteristics of students \\
$n(\%)$ \\
\hline Gender & \\
Female & \\
Male & \\
Age & $195(80.6)$ \\
20 or less & $47(19.4)$ \\
21 & \\
22 & $38(15.7)$ \\
23 & $52(21.5)$ \\
24 or more & $86(35.5)$ \\
Year & $48(19.8)$ \\
First year & $18(7.4)$ \\
Second Year & \\
Third Year & \\
Fourth Year & $6(2.5)$ \\
Courses & $68(28.1)$ \\
Psychology & $85(35.1)$ \\
Humanresource & $83(34.3)$ \\
Technology Management & \\
Accounting & $54(22.3)$ \\
Marketing & $58(24.0)$ \\
& $55(22.7)$ \\
Smartphone's Brand & $56(23.1)$ \\
Apple & $19(7.9)$ \\
Samsung & \\
Sony & \\
HTC & \\
Others & \\
& \\
& $26(10.7)$ \\
& $99(40.9)$ \\
& $28(11.6)$ \\
& $7(2.9)$ \\
& $82(33.9)$ \\
&
\end{tabular}

\subsection{The Personality of Undergraduate Students in Faculty Management}

Table 2 shows the descriptive analysis of items for big five personality. The highest mean among personality dimension was for Agreeableness, in which the mean score for this dimension was 3.65 and a standard deviation 0.57 . The second highest mean was extraversion with 3.59 and standard deviation of 0.56 . Conscientiousness had a mean score of 3.62 and standard deviation of 0.51 . The mean score of Neuroticism was 3.59 and standard deviation was 0.56 . Finally, the mean score for Openness was 3.63 and the standard deviation was 0.57 .

Table 2: Descriptive Analysis of Personality

\begin{tabular}{|c|c|c|c|c|c|}
\hline & Extraversion & Agreeableness & Conscientiouness & Neuroticism & Openness \\
\hline MEAN & 3.59 & 3.65 & 3.62 & 3.59 & 3.63 \\
\hline SD & 0.56 & 0.57 & 0.51 & 0.56 & 0.57 \\
\hline
\end{tabular}

*SD $=$ Standard Deviation 


\subsection{The Brand Personality of the Product Consume by the Undergraduate Students in Faculty of Management}

From Table 3, the mean score of 3.62 and the standard deviation of 0.52 was shown through the descriptive analysis in which Excitement had the highest value among all the brand personality. The total mean score for Competence was 3.64 and the standard deviation was 0.58 . Next, the Sincerity had a total mean score of 3.62 and the standard deviation was 0.52. The mean score for Sophistication was 3.60 and the standard deviation was 0.67 . The lowest mean was that for Ruggedness, where the mean was 3.40 and the standard deviation was 0.61 .

Table 3: Descriptive Analysis of Brand Personality

\begin{tabular}{|c|c|c|c|c|c|}
\hline & Sincerity & Excitement & Competence & Sophistication & Ruggedness \\
\hline MEAN & 3.62 & 3.69 & 3.64 & 3.60 & 3.40 \\
\hline SD & 0.52 & 0.59 & 0.58 & 0.67 & 0.61 \\
\hline
\end{tabular}

${ }^{*} \mathrm{SD}=$ Standard Deviation

\subsection{The Relationship between Brand Personality and Consumers' Personality among Undergraduate Students in Faculty of Management}

In table 4, the correlation coefficients of brand personality and consumers' big five personality were shown. From the results, it could be observed that the dimension of brand personality had high correlation with the dimension of big five personality since the significant values for both dependents and independent variables were 0 .

The Sincerity dimension had a significant and high correlation with Agreeableness as its Pearson correlation was 0.876. However, Sincerity had a higher correlation with Conscientiousness with a Pearson correlation value as high as 0.881. Meanwhile, the Excitement dimension had significant and high correlation with the Openness dimension with a Pearson value of 0.92 . For Competence, although it had significant and high correlation with Conscientiousness (Pearson correlation $=0.82$ ), the value of correlation was lower than the other big five personalitys dimension such Neuroticism (Pearson correlation $=0.89)$, Extraversion (Pearson correlation $=0.90)$, Agreeableness (Pearson correlation $=0.88)$ and Openness (Pearson correlation $=0.87$ ). In addition, Sophistication and Extraversion had a significant correlation, though the correlation with Openness was higher as shown in the results. Lastly, Ruggedness and Neuroticism also had a significant correlation (Pearson correlation $=0.73$ ), even though the correlation between Ruggedness and Extraversion was much higher (Pearson correlation $=0.77$ ).

Table 4: Correlation Coefficient

\begin{tabular}{|c|c|c|c|c|c|c|}
\hline & & EXT & AGR & CON & NEU & OPN \\
\hline SIN & $r$ & $.817^{\text {t* }}$ & $.876^{\star \star}$ & $.881^{\star *}$ & $.845^{\text {** }}$ & $.791^{* *}$ \\
\hline EXC & $r$ & $.846^{* *}$ & $.866^{* *}$ & $.828^{* *}$ & $.845^{\text {tk }}$ & $.917^{\text {t* }}$ \\
\hline COM & $r$ & $.894^{*+*}$ & $.884^{* *}$ & $.824^{* *}$ & $.896^{\text {tk }}$ & $.866^{* t}$ \\
\hline SOP & $r$ & $.801^{* *}$ & $.830^{* *}$ & $.811^{* *}$ & $.794^{* *}$ & $.860^{\text {t* }}$ \\
\hline RUG & $r$ & $.777^{* *}$ & $.682^{* *}$ & $.689^{* *}$ & $.743^{* *}$ & $.724^{* *}$ \\
\hline
\end{tabular}

Note: EXT = Extraversion, AGR = Agreeableness, CON= Conscientiousness, NEU = Neuroticism, OPN= Openness, SIN= Sincerity, EXC= Excitement, $\mathrm{COM}=$ Competence, $\mathrm{SOP}=$ Sophistication, RUG= Ruggedness; $* *=(p<0.01) ; r=$ Pearson Correlation

\subsection{The Effect of Brand Personality to Consumer's Personality among Undergraduate Students in Faculty of Management}

According to Table 5, brand personality had an effect on consumers' personality, in which the significant value was.000, indicating that there was a high significance between brand personality and consumer personality. The $\mathrm{R}^{2}$ value was 0.091, showing that brand personality had only a 9\% effect on Consumers' Personality.

In addition, Table 6 showed that the Multiple Regression of Brand Personality dimensions to big five Personality Dimension were highly correlated. Sincerity showed that it had a significant prediction on Agreeableness $\left(R^{2}=78 \%\right)$, Conscientiousness $\left(\mathrm{R}^{2}=78 \%\right)$, Extraversion $\left(\mathrm{R}^{2}=78 \%\right)$ and Neuroticism $\left(\mathrm{R}^{2}=71 \%\right)$.

Moreover, Excitement had significant effect on all five dimensions of big five Personality. It had the highest $\mathrm{R}^{2}$ value with Agreeableness $\left(R^{2}=78 \%\right)$ and the second highest value with Openness $\left(R^{2}=87 \%\right)$. The multiple regression of 
Competence had high and significant prediction on Agreeableness $\left(R^{2}=90 \%\right)$, followed by Openness $\left(R^{2}=89 \%\right)$ and Neuroticism $\left(R^{2}=78 \%\right)$.

Meanwhile, Sophistication had significant and high prediction on Openness $\left(R^{2}=91 \%\right)$, Agreeableness $\left(R^{2}=90 \%\right)$, Neuroticism $\left(\mathrm{R}^{2}=87 \%\right)$ and Extraversion $\left(\mathrm{R}^{2}=86 \%\right)$. There were three highly significant predictions for Ruggedness which were Openness $\left(R^{2}=92 \%\right)$, while Neuroticism and Extraversion had the same value of $R^{2}=89 \%$.

Table 5: Multiple Regression of Brand Personality

\begin{tabular}{|c|c|c|c|c|c|c|}
\hline Model & $\mathbf{R}$ & $\mathbf{R}^{2}$ & Adjust R & SE of the Estimate & $\mathbf{F}$ & Sig. \\
\hline Regression & 0.302 & 0.091 & .087 & .21 & 24.018 & .000 \\
\hline \multirow{2}{*}{ Model } & \multicolumn{2}{|c|}{ Unstandardized Coefficients } & Standardized Coefficients & \multirow{2}{*}{$\mathrm{t}$} & \multirow{2}{*}{ Sig. } \\
\cline { 2 - 8 } & $\mathrm{B}$ & Std. Error & Beta & 4.90 & .000 \\
\hline \multicolumn{2}{|c|}{ Brand Personality } & 0.13 & 0.03 & 0.30 & & \\
\hline
\end{tabular}

Table 6: Multiple Regression of Brand Personality

\begin{tabular}{|c|c|c|c|c|c|c|}
\hline & & EXT & AGR & CON & NEU & OPN \\
\hline SIN & $\mathrm{R}^{2}$ & $0.67^{\text {t*t }}$ & $0.78^{\text {t* }}$ & $0.78^{\text {t*t }}$ & $0.71^{* *}$ & 0.63 \\
\hline EXC & $\mathrm{R}^{2}$ & $0.80^{\text {t* }}$ & $0.88^{\text {t* }}$ & $0.85^{\text {t* }}$ & $0.82^{*+4}$ & $0.87^{* *}$ \\
\hline COM & $\mathrm{R}^{2}$ & $0.86^{\text {th }}$ & $0.90^{\text {t* }}$ & 0.87 & $0.87^{\text {t* }}$ & $0.89^{*+*}$ \\
\hline SOP & $\mathrm{R}^{2}$ & $0.86^{*}$ & $0.90^{\text {t* }}$ & $0.87^{\text {t* }}$ & 0.87 & $0.91^{* *}$ \\
\hline RUG & $\mathrm{R}^{2}$ & $0.89^{\text {th }}$ & 0.90 & $0.87^{*}$ & $0.89^{*+*}$ & $0.92^{* *}$ \\
\hline
\end{tabular}

Note: EXT = Extraversion, AGR = Agreeableness, $\mathrm{CON}=$ Conscientiousness, NEU $=$ Neuroticism, OPN= Openness, $\mathrm{SIN}=$ Sincerity, EXC= Excitement, $\mathrm{COM}=$ Competence, $\mathrm{SOP}=$ Sophistication, RUG= Ruggedness; ${ }^{* *}=(p<0.01) ; r=$ Pearson Correlation

\section{Discussion}

The first objective was to find out what is the most dominant personality among the undergraduate students in Faculty of Management. Results showed that Agreeableness was the most dominant trait in which most of the students in Faculty of Management were friendly, cooperative, trusting, and warm. According to Friedman and Schustack (2011), individuals with the Agreeableness trait tend to be sympathetic, helpful, trusting and cooperative.

The Extraversion and Neuroticism traits among undergraduates in Faculty of Management had the lowest mean, indicating that the students had energetic approach towards the social and material world, could socialize, were active and assertive. Specifically, students with the Extraversion trait were physically active and look for accompaniment and action. They would spend more time on socializing rather than on homework which was perceived as less beneficial in learning (Hendriks, Kuyper, Lubbers, \& Werf, 2011). Besides that, it was found that few students in Faculty of Management had the tendency to skip class because of their Neuroticism traits.

The second objective was to identify the brand personality of the product consumed by the respondents. The product's brand personality with the highest mean could be associated with the trait of Excitement. According to Park (2011), this result showed that brand excitement attracted consumers who see themselves as exciting individuals. The second highest mean was for the Competence trait, in which such students were likely to the products with nice quality or superior attributes (Hayes, 1999), which was also the most preferred by achiever customers (Aaker, 1995). Results also showed that students who strive to be competent in their study were more likely to have the products' competence traits match with their actual self (Parker, 2005).(Bouhlel, Mzoughi, Hadiji, \& Slimane, 2010)

The Sincerity and Sophistication traits were moderately high among the undergraduate students, tin which the more consumers trusted the product, the more they relate them with sincerity traits (Bouhlel et al., 2010). The Sophistication product's attribute were glamorous, smooth and charming (Park, 2011), Students who like products of sophistication may prefer brands such as Porsche (Aaker, 1995).

Lastly, Ruggedness trait had the lowest mean score in brand personality. Products with Ruggedness traits were chosen by undergraduate students most probably due to their characteristics of being tough and masculine. The low mean score may be attributed to only a few respondents being male students. In fact, most of the Ruggedness products were related to sports imagery advertisement (Hayes, 1999).

For objective three, five hypotheses in this study have been proven through the results of Pearson Correlation ( $r$ ). The correlation results showed that all the dimensions had high and significant correlations, even though it was not 
supported by previous research. Similar to the others, Sincerity traits were related to the Conscientiousness and Agreeableness traits (Aaker, 1997; Geuens et al., 2009). The Sincerity in this research was found to have correlation with Agreeableness, Conscientiousness, Openness, Extraversion and Neuroticism, thus proving that the hypothesis $(\mathrm{H} 1 \mathrm{a})$ was correct. Meanwhile, Excitement was found to be correlated with Extraversion, Openness, Conscientiousness, Neuroticism, and Agreeableness, proving that Hypothesis $(\mathrm{H} 1 \mathrm{~b})$ was correct because Excitement had relation with Openness even though previous studies found a relation with Extraversion (Aaker, 1997), and Conscientiousness (Ghorbani \& Mousavi, 2014).

In addition, the Competence traits were found to be correlated with the Conscientiousness and Extraversion traits (Aaker, 1995; Geuens et al., 2009; Ghorbani \& Mousavi, 2014). Still, this study found that Competence was also related with other personality traits such as Openness, Agreeableness and Neuroticism, proving that the hypothesis $(\mathrm{H} 1 \mathrm{c})$ was correct. According to Aaker (1997), the Sophistication and Ruggedness dimensions was not found to have correlation with any dimensions in big five personality. However, the results for this study contradicted that of Aaker's, in which it was shown that Sophistication and Ruggedness had significant relation with Openness, Conscientiousness, Agreeableness, Extraversion and Neuroticism. These proved that hypothesis $(\mathrm{H} 1 \mathrm{~d})$ and hypothesis $(\mathrm{H} 1 \mathrm{e})$ in this study were both correct because Sophistication had relation with Extroversion traits while Ruggedness had relation with Neuroticism traits.

The last objective of the study was to identify the impact of brand personality on the dimensions of consumer personality in making decision to buy products. Based on the results, the dimensions of brand personality had a high and significant influence on the dimensions of big five personality traits, even though there was lack of studies to support the results. Overall, the influence of brand personality on consumers' personality was significant, with $R^{2}=9 \%$.

These indicated that the effects were only obvious when using brand personality's dimensions to influence consumer personality dimension. After inserting all the dimensions of brand personality into a product, this product may be less likely to affect consumer's personality. This was because when the product did not have an outstanding brand personality such as Sincerity, Excitement, Competence, Sophistication, Ruggedness. Thus, people could not detect the product's personality, especially when the product with an outstanding brand personality such as that of Sincerity was much more attractive to consumers with the traits of Extraversion, Agreeableness, and Conscientiousness. The multiple regressions of this research also had a lack of support from previous research which focused on brand personality's effect on consumers' personality.

\section{Limitations}

The limitation of the study was that the results were only applicable in Faculty of Management, UTM because the sample did not represent other faculties in the university, thus were not applicable to other universities as well. The age and gender of respondents were also the limitations of this study. Most of the respondents in this study were female, therefore the results may be less applicable to male students. Besides that, the product was focused on Smartphone in order to reach a consensus related to respondents' rating of their products' brand personality. However, this caused the results to be unable to apply to other products.

Lastly, the results of study also lack support on the multiple regression table, perhaps due to a lack of research that investigate the aspects of brand personality which could affect the dimensions of big five personality, in which previous research were only related to brand loyalty (Ghorbani \& Mousavi, 2014; Hock, 2012; Long-Yi, 2010) and brand personality of a specific brand (Champniss \& Vila, 2011; Ferrandi et al., 2002; Mikkelsen; Thomas \& Sekar, 2008; Till \& Heckler, 2009).

\section{Recommendation and Conclusion}

From the study, several recommendations for the future could be proposed. One of the suggestions for the future study is to about this topic was the population can be set a larger population from the university rather than choosing students from a specific faculty as respondents. A larger sample could represent undergraduate students' personality and brand personality traits.

The conclusion of this study found that brand personality and consumers' personality were highly correlated. Moreover, the dimensions of brand personality also showed effect on the dimensions of personality.

The study highlighted that there were some aspects in this area or country which were not exposed or investigated by the researcher. However, there were too few support on the results of this study. Nevertheless, this study could help future research gain some details for comparison. Overall, more studies should be done on this aspect to enhance the knowledge of brand personality and personality in the Malaysian context. 


\section{Implication for Organization}

This study can be applied in the marketing field. First, the marketing department can show the brand personality of the product in the advertisement, by using actors or characters which have a personality (agreeableness) that can be linked with the brand personality traits (sincerity). This would indirectly attract individuals with similar personality, thus indirectly increase sales and amount of customers. For example, the LG phone which was more likely to be associated with the Sincerity trait may be less attractive for consumers with the Openness personality. Thus, the manager of LG could highlight the Ruggedness traits of LG phones through advertisements in order to attract consumers with Openness traits.

The second suggestion to the marketing manager is to make one of the brand personality traits to be outstanding, because the brand personality is more attractive when the personality is obvious. Too much brand personality traits on a product cause the product to have little or no personality at all. This is because the results in this study showed that the effect of brand personality dimensions was higher when it was focused on one of the traits compared to no particular obvious traits.

\section{References}

Aaker, J. L. (1995). Brand personality: Conceptualization, measurement and underlying psychological mechanisms. (9602828 Ph.D.), Stanford University, Ann Arbor. Retrieved from https://vpn.utm.my/docview/304216324?accountid=41678 ProQuest Central; ProQuest Dissertations \& Theses Full Text database.

Aaker, J. L. (1997). Dimensions of brand personality. JMR, Journal of Marketing Research, 34(3), 347-356.

Abdul, Y. R., \& Jevons, H. O. a. C. (2009). Do You See What I See? The Acceptance of Brand Personality by Individualist and Collectivist Cultures.

Aminuddin, A. (2014). Samsung Galaxy Note 4 rolls out into stores today. http://www.hardwarezone.com.my/tech-news-samsunggalaxy-note-4-rolls-out-stores-today

Bhargava, R. (2008). Personality Not Included: Mc Graw Hill.

Bouhlel, O., Mzoughi, N., Hadiji, D., \& Slimane, I. B. (2010). Brand Personality's Influence on the Purchase Intention: A mobiel marketing case. International Journal of Business and Management, 6.

Carlson, B. D., Donavan, D. T., \& Cumiskey, K. J. (2009). Consumer-brand relationships in sport: brand personality and identification. International Journal of Retail \& Distribution Management, 37(4), 370-384.

Champniss, G., \& Vila, F. R. (2011). Brand Value: How Socially Valued Brand Hold the Key to a Sustainable Future and Business Success: Wiley.

Cohen, M. (2010). Buy Me!:New Ways to Get Customers to Choose Your Product and Ignore the Rest.

Ekhlassi, A., Nezhad, M. H., Far, S. A., \& Rahmani, K. (2012). The relationship between brand personality and customer personality, gender and income: A case study of the cell phone market in Iran. Journal of Targeting, Measurement and Analysis for Marketing.

Engler, B. (2009). Personaltiy Theories (eight ed.): Houghton Mifflin Harcourt Publishing Company.

Ferrandi, J.-M., Merunka, D., Valette-Florence, P., \& Barnier, V. D. (2002). Brand Personality: How Well Does a Human Personality Scale Apply to Brands? Asia Pacific Advances in Consumer Research Volume 5, Pg 53-60.

Franzen, G., \& Moriarty, S. (2009). The Science and Art of Branding: ME Sharpe.

Friedman, H. S., \& Schustack, M. W. (2011). Personality: Classic Theories and Modern Research (fourth ed.): Pearson International edition.

Geuens, M., Weijters, B., \& De Wulf, K. (2009). A new measure of brand personality. International Journal of Research in Marketing, 26(2), 97.

Ghorbani, H., \& Mousavi, S. M. (2014). The Study Impact of Consumer Personality Traits on Brand Personality and Brand Loyalty. International Journal of Academic Research in Business and Social Sciences.

Hayes, J. B. (1999). Antecedents and Consequences of Brand Personality A Dissertation Submitted to the Faculty of Mississippi State University in Partial Fulfillment of the Requirements for the Degree of Doctor of Business Administration in Business Administration in the College of Business and Industry.

Hendriks, A. A. J., Kuyper, H., Lubbers, M. J., \& Werf, M. P. C. V. D. (2011). Personality as a Moderator of Context Effects on Academic Achievement. Journal of School Psychology, 49.

Hock, T. K. (2012). The Relationship of Concumer Brand Personality, Brand Personality, Brand Loyalty Towards Canon Digital Camera.

John, O. P., \& Srivasta, S. (1999). The Big Five Traits Taxanomy: Hisotry, Measurement, and Theoretical Perspectives Handbook of Personality: Theory and Research (2nd ed.).

King, S. (2007). A Master class in Brand Planning: The Timeless Works of Stephen King: WILEY.

Krejcie, R. V., \& Morgan, D. W. (1970). Determining Sample Size For Research Activity. Educational and Psychological Measurement, $30,607-610$.

Lin, L.-Y. (2010). The relationship of consumer personality trait, brand personality and brand loyalty: an empirical study of toys and video games buyers. Journal of Product \& Brand Management, 19(1), 4-17. 
Long-Yi, L. (2010). The relationship of consumer personality trait, brand personality and brand loyalty: an empirical study of toys and video games buyers. The Journal of Product and Brand Management, 19(1), 4-17. doi: http://dx.doi.org/10.1108/10610 421011018347

Mikkelsen, P. Brand Personality: Communicating Character and Authenticity in a Digital World. http://www.brandchannel.com/images/ papers/406_brand_personality_final.pdf

Park, J. K. (2011). The Influence of Brand Personalities on Consumers: Exploring the Moderating Role of Implicit Self-Theories.

Parker, B. T. (2005). This Brand's for Me: Brand Personality and User Imagery Based Self-Congruity.

Renner, T., Feldman, R. S., Morrissey, J., Mae, L., \& Major, M. (2011). Psychsmart: McGraw Hill.

Shoda, Y., Mischel, W., \& Smith, R. E. (2004). Introduction To personality: Toward an Integration (7th ed.): WILEY.

Thomas, B. J., \& Sekar, P. C. (2008). Measurement and Validity of Jennifer Aaker's Brand personality Scale for Colgate Brand. VIKALPA, 33(3), 49-61.

Till, B. D., \& Heckler, D. (2009). the Truth About Creatig Brands People Love: FT Press. 